\title{
BMJ
}

CHRISTMAS 2008: SPORT

\section{Mortality on Mount Everest, 1921-2006: descriptive study}

\author{
Paul G Firth, anaesthetist, ${ }^{1}$ Hui Zheng, statistician, ${ }^{2}$ Jeremy S Windsor, specialist registrar in anaesthetics \\ and intensive care, ${ }^{3}$ Andrew I Sutherland, Wellcome research training fellow, ${ }^{4}$ Christopher H Imray, \\ vascular surgeon, ${ }^{5}$ G W K Moore, professor, ${ }^{6}$ John L Semple, professor, ${ }^{7}$ Robert C Roach, associate \\ professor, ${ }^{8}$ Richard A Salisbury, computer analyst ${ }^{9}$
}

Department of Anesthesia and

Critical Care, Massachusetts General Hospital, Boston, MA 02114, USA

${ }^{2}$ Biostatistics Center,

Massachusetts General Hospital, Boston

${ }^{3}$ Heart Hospital, London

${ }^{4}$ Nuffield Department of Surgery, John Radcliffe Hospital, Oxford

${ }^{5}$ Department of Surgery, University Hospital, Coventry

${ }^{6}$ Department of Physics, University of Toronto, Canada

${ }^{7}$ Department of Surgery, University of Toronto

${ }^{8}$ University of Colorado Denver Health Sciences Center, Aurora, Colorado, USA

${ }^{9}$ Ann Arbor, Michigan, USA Correspondence to: P Firth pfirth@partners.org

Cite this as: BMJ 2008:337:a2654 doi:10.1136/bmj.a2654

\section{ABSTRACT}

Objective To examine patterns of mortality among climbers on Mount Everest over an 86 year period. Design Descriptive study.

Setting Climbing expeditions to Mount Everest, 19212006.

Participants 14138 mountaineers; 8030 climbers and 6108 sherpas.

Main outcome measure Circumstances of deaths. Results The mortality rate among mountaineers above base camp was $1.3 \%$. Deaths could be classified as involving trauma (objective hazards or falls, $n=113$ ), as non-traumatic (high altitude illness, hypothermia, or sudden death, $n=52$ ), or as a disappearance (body never found, $n=27$ ). During the spring climbing seasons from 1982 to $2006,82.3 \%$ of deaths of climbers occurred during an attempt at reaching the summit. The death rate during all descents via standard routes was higher for climbers than for sherpas $(2.7 \%(43 / 1585) \vee 0.4 \%$ (5/1231), P<0.001; all mountaineers 1.9\%). Of 94 mountaineers who died after climbing above $8000 \mathrm{~m}$, $53(56 \%)$ died during descent from the summit, $16(17 \%)$ after turning back, 9 (10\%) during the ascent, 4 (5\%) before leaving the final camp, and for 12 (13\%) the stage of the summit bid was unknown. The median time to reach the summit via standard routes was earlier for survivors than for non-survivors (0900-0959 v 1300-1359, P 0.001). Profound fatigue $(n=34)$, cognitive changes $(n=21)$, and ataxia $(n=12)$ were the commonest symptoms reported in non-survivors, whereas respiratory distress $(n=5)$, headache $(n=0)$, and nausea or vomiting $(n=3)$ were rarely described.

Conclusions Debilitating symptoms consistent with high altitude cerebral oedema commonly present during descent from the summit of Mount Everest. Profound fatigue and late times in reaching the summit are early features associated with subsequent death.

\section{INTRODUCTION}

At $8850 \mathrm{~m}$ above sea level, the summit of Mount Everest is the highest point on earth. Since the 1920s, thousands of mountaineers have tried to scale Everest, and many have died during the attempt. Despite this,
Everest and other major peaks in the Himalayan mountain range continue to attract increasing numbers of climbers, with a significant associated mortality during expeditions. ${ }^{1-6}$ We examined the circumstances of deaths on Mount Everest to establish patterns of mortality among mountaineers on a large Himalayan peak.

\section{METHODS}

We carried out a retrospective study of all deaths during climbing expeditions on Everest during 1921-2006. The population studied included all members (listed on expedition permits) and employees of these expeditions. We identified deaths through published accounts of expeditions and by searching the Himalayan Database, a computerised registry of climbing expeditions to registered peaks in the Nepalese Himalayas. ${ }^{4}$ We located accounts of deaths from these sources, by searching the internet or by direct contact with mountaineers. We classified the source of the reports as direct contact (interview or correspondence with the authors), miscellaneous, or based on accounts in journals, books, the Himalayan Database, and the internet. We classified the reports by authorship: eyewitness, expedition members or employees who were not eyewitnesses, or secondary (authors not part of the expedition).

For statistical purposes we counted repeat visits and successes on reaching the summit as independent events. We defined the altitude of death as that at which a fatality occurred or was estimated to have occurred, from where a fall occurred, or from where a nonsurvivor was initially evacuated. A fatal incident was defined as an event involving one or more people on the same expedition, or climbing together, during a single trip between camps. In incidents where mountaineers died at different altitudes, we estimated the altitude of the incident. Base camp was defined as the final encampment on any route before technical (roped) climbing began.

Four doctors who were experienced in managing high altitude illness independently examined the accounts of deaths. Three of these reviewers had 


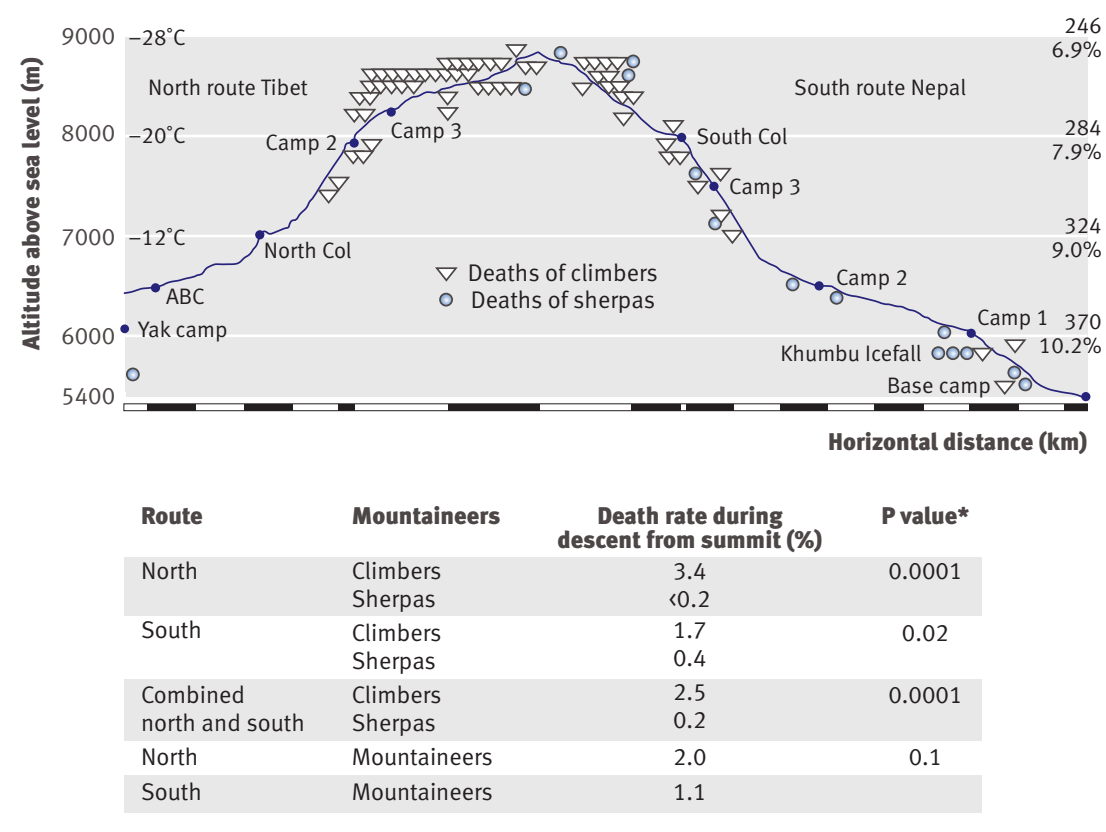

Fig 1 | Deaths on standard north and south routes of Everest during spring climbing season (April-June) 1982-2006. Deaths during descent are above route profile and deaths before summiting or during bids for summit with unknown outcome are below. One sherpa died below Yak camp during evacuation. Right axis shows estimated barometric pressure during May, ${ }^{14}$ and percentage of oxygen at sea level $(760 \mathrm{~mm} \mathrm{Hg})$ that exerts equivalent partial pressure to atmospheric oxygen at relevant altitude. Left axis shows estimated ambient air temperature during May. ${ }^{1516}$ Scale on $\mathrm{x}$ axis is expanded by factor of two for route above $8000 \mathrm{~m}$. *Two sided Fisher's exact test univariable analyses of binary and categorical outcomes we used a $\chi^{2}$ test or Fisher's exact test. We used the two sided $t$ tests or a Wilcoxon rank sum test to compare continuous outcomes, including summit time and the number of deaths due to objective hazards per incident, whenever appropriate. We used SAS software version 9 as the main tool for statistical analysis.

\section{Weather analysis}

To assess the role of adverse weather in fatal incidents, we examined the accounts of deaths during May from 1975 to 2006 , as this period included most deaths. Each reviewer independently scored the probability that adverse weather contributed to a fatal outcome as very probable (score 1), probable (2), possible (3), or unlikely or unknown (4). By adding these weather scores together, we identified days when deterioration in weather probably did (score $\leq 8)$ or $\operatorname{did} \operatorname{not}(>8)$ play a part in deaths above $7000 \mathrm{~m}$. We also identified days on the summit without deaths from the Himalayan Database. ${ }^{4}$ The representative meteorological conditions of days with these three outcomes were then computed using a compositing technique for the barometric pressure at $9000 \mathrm{~m}$ above sea level, based on fields from the reanalysis project of the National Center for Environmental Prediction, ${ }^{10}$ a dataset that includes all available meteorological observations and that is applicable to analysis of weather conditions on Everest. $^{11-13}$

\section{RESULTS}

Table 1 outlines the characteristics of the study population. Overall, 341 accounts were analysed, including 136 notes from the Himalayan Database, 106 journal reports, 31 books, 32 direct accounts by 22 climbers, 14 web based accounts, and 7 miscellaneous sources. In total, 154 fatal incidents resulting in 212 deaths were identified. Of these deaths, 72 were reported by at least an eyewitness author, 55 by at least an expedition member author, and the remaining 85 were solely by secondary authorship. Survivors witnessed 127 deaths or the immediate circumstances of death (objective hazard, sudden death, in extremis, immediate evidence of a fall), 58 immediate circum stances had not been witnessed but the body was found, and 27 people had disappeared without their final moments being reported.

For the classification of all 212 deaths, there was unanimous independent agreement for 165 (78\%) of the classifications. The Fleiss $\kappa$ value for inter-rater agreement was $0.63, \mathrm{P}<0.001$ (substantial agreement). ${ }^{9}$ Of deaths classified at all altitudes, fatal cerebral oedema occurred at a higher altitude than fatal pulmonary oedema (7 $v$ 5; 8276 (SD 791) m $v 6229$ (SD 104) $\mathrm{m}, \mathrm{P}=0.001$ ). Table 2 provides the classification of deaths above base camp; see www.himalayan database.com for further data. ${ }^{4}$

Above base camp, 103 incidents involving climbers occurred at a higher mean altitude than 44 involving sherpas (7854 (SD 918) m v6927 (SD 116) m, P<0.001). Thirty seven incidents involved objective hazards, with

\section{Statistical analysis}

We used the Fleiss' kappa method to analyse the interrater agreement for classification of death. ${ }^{9}$ For 
more sherpas killed per incident than climbers $(1.18 v$ $0.54, \mathrm{P}=0.02)$. The mean altitude of events involving objective hazards was 6381 (SD 661) $\mathrm{m}$.

The death rate during all descents from the summit via the standard routes was higher for climbers than for sherpas $(2.7 \%(43 / 1585)$ v $0.4 \%(5 / 1231), \mathrm{P}<0.001$; all mountaineers $1.9 \%$ ). Figure 1 presents the mortality and distribution of deaths on the standard routes during the spring climbing seasons of 1982 to 2006. Of 77 deaths, 55 occurred during bids for the summit (51 climbers, four sherpas, 71\%) and 22 during preparation of the route (11 climbers, 11 sherpas, 29\%). Six incidents involving objective hazards resulted in eight deaths on the standard south route; no deaths occurred on the north route in this category.

Table 3 presents data on the mountaineers who died after reaching $8000 \mathrm{~m}$. Fifty three (56\%) died during the descent, 16 (17\%) after turning back below the summit, and nine $(10 \%)$ during the ascent. The stage of the summit bid was unknown for 12 mountaineers (13\%), and four $(5 \%)$ died before leaving the final camp. Of a subset of 23 mountaineers who climbed without supplemental oxygen, $11(48 \%)$ died during the descent, 4 (17\%) after turning back, and 4 (17\%) during the ascent, and in $4(17 \%)$ the stage was unknown. Median time to reach the summit via standard routes was earlier for survivors than for non-survivors (09000959 (interquartile range $0800-0859$ to $1100-1159$ ) $v$ 1300-1359 (1100-1159 to 1600-1659), $\mathrm{P}<0.001$ ). Thirty seven mountaineers died or were in extremis in the presence of witnesses, 34 fell behind team members before becoming debilitated or dying, the circumstances of 11 were unknown as they died with all team members and therefore without report, 11 climbed alone, and one could not be classified as the account was insufficient.

Of these 94 mountaineers who died, 33 had symptoms attributable to high altitude illness and six had symptoms of either high altitude illness or

Table 1|Population characteristics of mountaineers on Everest, 1921-2006. Values are numbers (percentages) unless stated otherwise

\begin{tabular}{lccc} 
Variables & Climbers $(\mathrm{n}=8030)$ & Sherpas $(\mathrm{n}=6108)$ & Total \\
Male & $7404(92.2)$ & $6106(99.9)$ & 13510 \\
\hline Female & $626(7.8)$ & $2(0.1)$ & 628 \\
\hline Mean (SD) age (years) (range) & $36.5(8.9)(12-74)$ & $-{ }^{\star}$ & - \\
\hline Overall total & 8030 & 6108 & 14138 \\
\hline Summit ascents: & & & \\
\hline $1953-81$ (all) & $94(5.3)$ & $23(1.8)$ & $13.8)$ \\
\hline $1982-2006:$ & $663(37.5)$ & $661(51.2)$ & $1324(43.3)$ \\
\hline S-spring & $732(41.4)$ & $484(37.5)$ & $1216(39.8)$ \\
\hline N-spring & $279(15.8)$ & $122(9.4)$ & $401(13.1)$ \\
\hline Other† & 1768 & 1290 & 3058
\end{tabular}

S-spring=standard Nepalese route via South Col or Southeast Ridge, or minor variants, during April to June; $\mathrm{N}$ spring=standard Tibetan route via North Col or Northeast Ridge, or minor variants, during April to June.

Population includes estimates of expedition size and roles of mountaineers (climbers or sherpas) for Chinese expeditions, 1960-79, on north side of Everest. Percentages may not add up to $100 \%$ owing to rounding. *Data were unreliable.

†All other routes such as West Ridge or North Face approaches, or attempts on all routes during seasons other than spring.

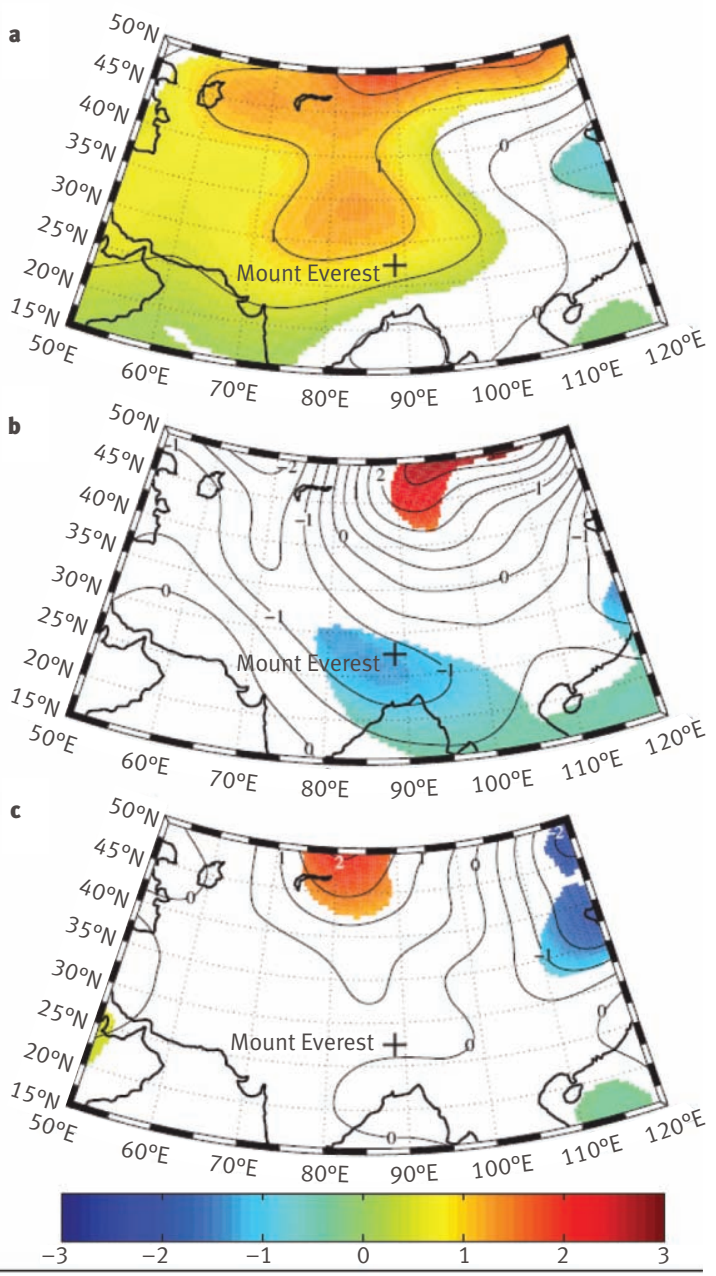

Fig 2 | Composite of barometric pressure (millibars), expressed as anomaly to long term mean pressure, at $9000 \mathrm{~m}$ above sea level over Asia during May 1975-2006. Shaded regions are those where barometric variations differ from mean pressure $(P<0.05)$, which is complied from a resampling technique with 1000 randomised samples at the same location. (a) Large region of higher than mean pressure ( $P<0.05)$ near Everest coincides with 141 days on which mountaineers reached the summit. (b) On days with weather related deaths above $7000 \mathrm{~m}$ (score $\leq 8)$, Everest is in region of lower than mean barometric pressure $(\mathrm{P}<0.05)$. (c) No statistically significant pressure anomaly present on those days when non-weather related deaths occurred above $7000 \mathrm{~m}$ (score 18 ). For days when mountaineers reached the summit, average pressure anomaly in vicinity of Everest varied from $-3 \mathrm{mb}$ to $5 \mathrm{mb}$, whereas for days in which a weather related death occurred, average pressure anomaly varied from $-6 \mathrm{mb}$ to $2 \mathrm{mb}$. For days in which a non-weather related death occurred, average pressure anomaly varied from $-4 \mathrm{mb}$ to $5 \mathrm{mb}$

hypothermia, or both. The symptoms and numbers of mountaineers, respectively, were profound fatigue or exhaustion $(n=34)$, confusion or coma (21), ataxia (12), respiratory disturbances (5), nausea or vomiting (3), and headache (0). Of 32 falls, 12 were not closely witnessed, eight involved climbers described as confused or exhausted, seven occurred in treacherous conditions, and in five cases the accounts were unclear. 
Table 2 |Classification of deaths of mountaineers climbing above base camp*, 1921-2006. Values are numbers of people killed unless stated otherwise

\begin{tabular}{lccc} 
Classification & Climbers & Sherpas & Total \\
Trauma: & 54 & 59 & 113 \\
\hline Objective hazards & 20 & 47 & 67 \\
\hline Falls & 34 & 12 & 46 \\
\hline Non-trauma: & 46 & 6 & 52 \\
\hline High altitude illness & 12 & 5 & 17 \\
\hline Hypothermia & 11 & 0 & 11 \\
\hline Sudden death & 7 & 0 & 7 \\
\hline Unclassified & 16 & 1 & 17 \\
\hline Disappeared & 25 & 2 & 27 \\
\hline Total & 125 & 67 & 192 \\
\hline Total death rate (\%) & 1.6 & 1.1 & 1.3 \\
\hline
\end{tabular}

*Last encampment on any route before technical (roped) climbing began (base camp in Nepal, advanced base camp in Tibet).

Of the 27 climbers who disappeared, 12 had evidence of neurological dysfunction or profound fatigue, 1 had pulmonary oedema, 9 may have fallen without evidence of previous dysfunction, and 5 disappeared without report of their condition. Of 11 deaths classified as high altitude illness, 6 were due to cerebral oedema, 2 involved cerebral oedema but possible subsequent respiratory difficulties, 1 involved both neurological and pulmonary symptoms, and 2 involved debilitating fatigue, the subsequent course of which was unclear. Of the 14 unclassified deaths, the relative contribution of hypothermia and high altitude illness was unclear in six climbers who collapsed or were found comatose, the non-traumatic deaths of six climbers found dead without adequate details were described as unknown, and in two cases accounts conflicted. Two climbers died suddenly (one had preexisting asthma, the other a brain tumour), one death involved a myocardial infarction, and two climbers collapsed suddenly from unknown causes. One climber had noticeable cognitive impairment and fatigue before developing severe hypothermia in a storm. Of seven cases of visual disturbances, four were painless, two were painful, and one was related to a brain tumour.

During May 1975 to 2006, deaths occurred on 31\% of days when mountaineers reached the summit (44/141; fig 2). Deterioration in weather played a part in $25 \%$ of deaths $(14 / 56)$ on $6 \%$ of these days $(8 / 141)$.

Table 3 |Classification of deaths above $8000 \mathrm{~m}$ on Everest. Values are numbers (percentages)

\begin{tabular}{lccc} 
Category & Climbers & Sherpas & Total \\
Fall & $23(28)$ & $9(75)$ & $32(34)$ \\
\hline Disappeared & $25(31)$ & $2(17)$ & $27(29)$ \\
\hline High altitude illness & $11(13)$ & 0 & $11(11)$ \\
\hline Unclassified & $13(16)$ & $1(8)$ & $14(15)$ \\
\hline Sudden death & $5(6)$ & 0 & $5(5)$ \\
\hline Objective hazard & $3(4)$ & 0 & $3(3)$ \\
\hline Hypothermia & $2(2)$ & 0 & $2(2)$ \\
\hline Total & $82(87)$ & $12(13)$ & 94
\end{tabular}

Percentages may not add up to $100 \%$ owing to rounding.
Figure 2 presents a chart of mean barometric pressure at $9000 \mathrm{~m}$ for days when mountaineers reached the summit, and for weather related deaths and nonweather related deaths above $7000 \mathrm{~m}$.

\section{DISCUSSION}

This study examined the patterns of deaths over an 86 year period on Mount Everest (1921-2006). The mortality above base camp was 1.3\% (table 2). Most sherpas were killed in incidents on the lower slopes, whereas most climbers died above $8000 \mathrm{~m}$. Climbers typically died during descent from the summit, often developing cognitive impairment and ataxia, symptoms of high altitude cerebral oedema. Profound fatigue, late summit times, and the tendency to fall behind companions were common early features of non-survivors.

\section{Strength and limitations}

The strength of this study lies in the meticulous records kept over four decades by Katmandu based journalist Elizabeth Hawley, whose work is the foundation of the Himalayan Database. ${ }^{4}$ An assessment of deaths was, however, limited by the variability of accounts and circumstances. While there was substantial agreement between the independent reviewers on classification of the deaths (Fleiss' $\kappa=0.63, \mathrm{P}<0.001),{ }^{9}$ categorisation was achieved using a descriptive classification system. This approach may underestimate underlying problems, such as neurological dysfunction leading to falls, disappearances, or vulnerability to hypothermia at extreme altitude. The widespread use of supplemental oxygen may affect physiological responses to altitude, and a precise association between altitude and symptoms cannot be made. Although a retrospective study can only show an association and not prove causality, this simple descriptive technique nevertheless allows for broad patterns of mortality to be detected.

\section{Comparison with other mountains}

The death rate among climbers on Denali (6194 m), Alaska, during $1903-2006$ was $0.03 \%,{ }^{17}$ whereas the overall death rate on Mount Rainier (4392 m), Washington, during $1987-1996$ was $0.02 \% .{ }^{15} 18$ The mortality among expedition members during 19502006 on Himalayan peaks such as Ama Dablam (6814 $\mathrm{m})$ and Cho Oyo $(8201 \mathrm{~m})$ were $0.46 \%$ and $0.65 \%$, respectively. ${ }^{6}$ As with Everest, these four peaks are scaled by large numbers of relatively inexperienced climbers using standard routes. ${ }^{6-18}$ The death rate on Everest is therefore greater than that of lower mountains attempted by similar populations of climbers.

\section{Distribution of deaths}

The largest class of deaths involved objective hazards such as avalanches, icefall collapses, crevasses, and falling rock. Sherpas were killed at a greater rate per incident than climbers $(1.18 v 0.54, \mathrm{P}=0.02)$, with $70 \%$ of deaths in sherpas classified in this category. These 


\section{WHAT IS ALREADY KNOWN ON THIS TOPIC}

The death rate on Mount Everest is greater than that of lower mountains attempted by similar populations of climbers

The death rate among climbers is higher than that among sherpas

\section{WHAT THIS STUDY ADDS}

Most climbers on Mount Everest die above $8000 \mathrm{~m}$, usually during descent from the summit

Cognitive impairment and ataxia, symptoms of cerebral oedema, are often present

Profound fatigue and late summit times are early features of non-survivors

incidents typically occurred on the lower sections of climbing routes, which pass below slopes prone to avalanches and include the Khumbu Icefall, an unstable section of glacier. The risk of death relates to the amount of time spent in areas where these hazards are likely to occur. Typical expeditions on Everest involve multiple trips to place camps on the route of a summit bid. As sherpas are employed to transport equipment, the higher death rate per incident among sherpas can largely be explained by more time spent in the danger zones on the lower sections of the routes.

Although Everest has been climbed by many routes during different seasons, ${ }^{5}$ over $83 \%$ of all ascents occurred during the spring along the standard routes in the last 25 years of the study period (table 1). In these expeditions, deaths from objective hazards were rare: six incidents on the Nepal route resulted in a total of eight deaths, while there were none on the Tibet route. By contrast, $85.4 \%$ of deaths on the north route and $43.9 \%$ of deaths on the south route occurred above $8000 \mathrm{~m}$ (fig 1). While a typical expedition to Everest now lasts about 60 days, $82.3 \%$ of deaths among climbers occurred during or after the day of a summit attempt. For modern climbers, therefore, the most dangerous time was that spent above $8000 \mathrm{~m}$.

\section{Deaths above $8000 \mathrm{~m}$}

In contrast to the deaths from objective hazards at lower altitudes, climbers died during the descent from the summit at a greater rate than did sherpas $(2.5 \%$ v $0.2 \%, \mathrm{P}<0.001)$. On the Tibet and Nepal routes, $3.4 \%$ and $1.7 \%$ of climbers, respectively, did not return from the summit. Gross cognitive impairment and ataxia were common among non-survivors. These progressive symptoms and delayed presentation are consistent with high altitude cerebral oedema, a vasogenic oedema predominantly caused by failure of vascular endothelial fluid regulation after inadequate acclimatisation to hypoxia. ${ }^{71920}$ Acute hypoxaemia during descent due to the exhaustion of supplemental oxygen supplies used by most climbers is another potential explanation for this distribution of symptoms. ${ }^{21} \mathrm{~A}$ similar pattern of death during descent is, however, seen in climbers with and without supplemental oxygen above $8000 \mathrm{~m}$. Arterial oxygenation decreases during strenuous exercise at high altitude, ${ }^{22} 23$ so maximal hypoxaemia would occur during vigorous exertion just below the summit. However, we identified only two cases of sudden death that occurred during active ascent, both in climbers using supplemental oxygen. Failures of supplemental oxygen circuits during ascent are not unusual, yet we did not detect any deaths directly attributable to this. Among non-survivors, neurological dysfunction and possibly the susceptibility to acute hypoxia after exhaustion of supplemental oxygen therefore typically progress with time at extreme altitude. This is characteristic of the cerebrovascular leak and disruption of fluid homoeostasis of high altitude cerebral oedema, rather than of acute hypoxaemia alone. In addition, hypoxic neurological dysfunction at extreme altitude may involve other pathophysiological mechanisms not prominent at lower elevations.

Respiratory distress, nausea, vomiting, and headache, common indicators of altitude illness at 2500$5000 \mathrm{~m},{ }^{719202425}$ were rarely noted in non-survivors above $8000 \mathrm{~m}$. This may be because people with these symptoms are more likely to survive because they turn back earlier. However, anecdotal accounts of the rapid onset of cerebral oedema at very high altitudes without preceding headache or vomiting have been reported. ${ }^{2627}$ The mechanisms of the headache of cerebral oedema are unclear but may relate to the acute distension of the afferent innervated blood vessels and meninges at the base of the brain during raised intracranial pressure. ${ }^{28}$ An acute decrease in intravascular volume is a normal physiological response to high altitude, ${ }^{29}$ and dehydration, due to the increased physiological demands and the practicalities of melting sufficient snow, is a common problem above $8000 \mathrm{~m}$. Acute decreases in fluid volumes may slow the increase in intracranial pressure and related headache after fluid extravasation. Ataxia and confusion may occur with a lesser degree of oedema, due to the hypoxaemia at extreme altitude. We speculate that at extreme altitude, headache, nausea, and vomiting are unreliable heralds of fatal cerebral oedema, whereas debilitating ataxia and impaired consciousness present earlier than these symptoms. Profound fatigue, reflected in significantly later summit times, was an early symptom of subsequent non-survivors.

Atmospheric factors other than hypoxia also compound physiological stress at extreme altitudes. ${ }^{1516}$ Although hypothermia and strong wind exacerbate the problems of a hypoxic environment, only 5.7\% of summit days during the peak summit month of May had deaths associated with weather that was worse than baseline $(8 / 141, \mathrm{P}<0.05)$. Painful retinal burns due to the intense ultraviolet radiation were identified only in two non-survivors. Mountaineering factors such as inexperience, inadequate teamwork, and the absence of protective ropes on the summit routes may play significant roles. However, similar problems might be expected on peaks such as Rainier and Denali, where the death rate is considerably lower. ${ }^{151718}$ The difficulty of rescue at extreme altitude undoubtedly increases mortality compared with lower altitudes, but this does not cause the primary problems leading to the need for rescue. Although these factors variously contribute to 
deaths, they cannot in isolation adequately explain the cluster of deaths at extreme altitude.

\section{Acclimatisation to extreme altitude}

Since neurological symptoms are present in many nonsurvivors, critical questions include whether adequate acclimatisation is possible at this altitude and, if so, how can it best be achieved. ${ }^{2130}$ Climbers died at over six times the rate of sherpas during the descent from the summit. Recent trends on the standard routes are for climbers to spend more time at lower altitudes before making a rapid ascent, whereas sherpas spend more time above base camp preparing the route. ${ }^{21}$ The differing mortality during descent may be related to better acclimatisation by sherpas due to prolonged time at higher altitudes. However, selection for employment during an expedition may involve a bias for the ability to perform at altitude. Most sherpas are of Sherpa extraction, an ethnic group from the Nepali highland whose name has become synonymous with the exceptionally hardy porters of high altitude. This group and others born and resident at high altitudes may have superior congenital and acquired adaptations to hypoxia compared with their lowland employers. ${ }^{3132}$ As employees, sherpas may be less likely to climb alone and hence are more likely to be rescued. While one subpopulation of mountaineers can acclimatise sufficiently to climb Everest using supplemental oxygen with relatively low mortality, the interaction and relative importance of the differences between populations and acclimatisation profiles requires further study.

We thank Gary Landeck and Mike Weichert (American Alpine Club Library, USA) and Yvonne Sibbald (Alpine Club Library, UK) for their help in locating articles; the many Everest mountaineers from around the world who patiently provided details of deaths; Charlie Cote and Scott Tolle (Massachusetts General Hospital) for assistance in the preparation of the manuscript; and Armin Gruen and Martin Sauerbier (Institute of Geodesy and Photogrammetry, Switzerland) for data and assistance in constructing the route profile.

Contributors: PGF, JSW, AIS, CHI, JLS, and RCR constructed the classification system. PGF collected the accounts and interviewed climbers. PGF, JSW, AIS, and CHI analysed the reports. GWKM and JLS analysed the weather patterns. RAS provided data from the Himalayan Database. $\mathrm{HZ}$ did the statistical analysis. PGF wrote the manuscript with input from all authors. PGF is the guarantor of data related to the circumstances of death. GWKM is the guarantor of meteorological data. RAS is the guarantor of data from the Himalayan Database.

Competing interest: RAS has a financial interest in the Himalayan Database.

Ethical approval: This study was approved by the institutional review board of Massachusetts General Hospital.

Provenance and peer review: Not commissioned; externally peer reviewed.

1 Town J. Death and the art of database maintenance. Mountain 1986;110:42-5.

2 Huey RB, Eguskitza X. Supplemental oxygen and mountaineer death rates on Everest and K2. JAMA 2000;284:181.
3 Eguskitza X, Huey RB. Supplemental oxygen and mountaineering deaths. 02 the extra breath of life on Everest and K2? Am Alpine J 2000;135-8.

4 Hawley E, Salisbury R. The Himalayan database: the expedition archives of Elizabeth Hawley. Golden, CO: American Alpine Club, 2004-7.

5 Huey RB, Salisbury R. Success and death on Mount Everest. How the main routes and seasons compare. Am Alpine J 2003:2-10.

6 Salisbury R, Hawley E. The Himalaya by the numbers. www. himalayandatabase.com. 2007.

7 Hackett PH, Roach RC. High-altitude illness. N Engl J Med 2001;345:107-14.

8 Roach RC, Bartsch P, Hackett PH, Oelz O, Lake Louise AMS Scoring Consensus Committee. The Lake Louise acute mountain sickness scoring system. In: Sutton JR, Houston CS, Coates G, eds. Hypoxia and molecular medicine. Burlington, VT: Charles S Houston, 1993:272-4.

9 Fleiss JL. Measuring nominal scale agreement amongst many raters. Psychol Bull 1971;76:378-82.

10 Kalnay E, Kanamitsu M, Kristler R, Collins W, Deaven D, Gandin L, et al. The NCEP/NCAR 40-year reanalysis project. Bull Am Meteorol Soc 1996;77:437-71.

11 Moore G, Alvertson K, Holdsworth G. The impact that elevation has on the ENSO signal in precipitation records from the Gulf of Alaska region. Clim Change 2003;59:101-21.

12 Moore G, Semple J. High Himalayan meteorology: weather at the South Col of Mount Everest. Geophys Res Lett 2004;31(18).

13 Moore G, Semple J. Weather and death on Mount Everest-an analysis of the into thin air storm. Bull Am Meteorol Soc 2006;87:465-80.

14 West JB. Prediction of barometric pressures at high altitude with the use of model atmospheres. J Appl Physiol 1996;81(4):1850-4.

15 Huey RB, EguskitzaX. Limits to human performance: elevated risks on high mountains. J Exp Biol 2001;204(Pt 18):3115-9.

16 West JB, Schoene RB, Milledge JS. High altitude medicine and physiology. 4th ed. London: Hodder Arnold, 2007:24-5.

17 Mclntosh SE, Campbell AD, Dow J, Grissom CK. Mountaineering fatalities on Denali. High Alt Med Biol 2008;9:89-95.

18 Christensen ED, Lacsina EQ. Mountaineering fatalities on Mount Rainier, Washington, 1977-1997: autopsy and investigative findings. Am J Forensic Med Pathol 1999;20:173-9.

19 Hackett PH, Yarnell PR, Hill R, Reynard K, Heit J, McCormick J. Highaltitude cerebral edema evaluated with magnetic resonance imaging: clinical correlation and pathophysiology. JAMA 1998;280:1920-5.

20 Wu T, Ding S, Liu J, Jia J, Dai R, Liang B, et al. Ataxia: an early indicator in high altitude cerebral edema. High Alt Med Biol 2006;7:275-80.

21 Boukreev A. The oxygen illusion: perspectives on the business of high-altitude climbing. Am Alpine J 1997:37-43.

22 Sutton JR, Reeves JT, Groves BM, Wagner PD, Alexander JK, Hultgren $\mathrm{HN}$, et al. Oxygen transport and cardiovascular function at extreme altitude: lessons from Operation Everest II. Int I Sports Med 1992;13(suppl 1):S13-8.

23 Imray CH, Myers SD, Pattinson KT, Bradwell AR, Chan CW, Harris S, et al. Effect of exercise on cerebral perfusion in humans at high altitude. J Appl Physiol 2005;99:699-706.

24 Maggiorini M, Buhler B, Walter M, Oelz O. Prevalence of acute mountain sickness in the Swiss Alps. BMJ 1990;301:853-5.

25 Hultgren HN, Honigman B, Theis K, Nicholas D. High-altitude pulmonary edema at a ski resort. West J Med 1996;164:222-7.

26 Clarke C. High altitude cerebral oedema. Int J Sports Med 1988;9:170-4

27 Thomassen O, Skaiaa SC. High-altitude cerebral edema with absence of headache. Wilderness Environ Med 2007;18:45-7.

28 Sutherland Al, Morris DS, Owen CG, Bron AJ, Roach RC. Optic nerve sheath diameter, intracranial pressure and acute mountain sickness on Mount Everest: a longitudinal cohort study. Br / Sports Med 2008;42:183-8

29 Pugh LG. Blood volume and haemoglobin concentration at altitudes above 18,000 Ft (5500 M). I Physiol 1964;170:344-54.

30 Pollard A, Clarke C. Deaths during mountaineering at extreme altitude. Lancet 1988;1:1277

31 Niermeyer S, Yang P, Shanmina, Drolkar, Zhuang J, Moore LG. Arteria oxygen saturation in Tibetan and Han infants born in Lhasa, Tibet. $N$ Engl J Med 1995;333:1248-52.

32 Erzurum SC, Ghosh S, Janocha AJ, Xu W, Bauer S, Bryan NS, et al. Higher blood flow and circulating NO products offset high-altitude hypoxia among Tibetans. Proc Natl Acad Sci USA 2007;104:17593-8.

Accepted: 9 November 2008 